\title{
The Reproducibility of the multiplex RAPD-PCR assay in genotyping of Mycobacterium tuberculosis isolates from Sulawesi, Indonesia
}

\author{
Mochammad Hatta ${ }^{1,}$, AndiRofian Sultan ${ }^{1}$, Ressy Dwiyanti ${ }^{1,3}$, Muhammad Sabir ${ }^{1,3}$, \\ Andini Febrianty ${ }^{1,3}$, Ahmad Adhyka ${ }^{1,3}$, Nur Indah Purnamasari ${ }^{2}$, Muhammad Reza Primaguna ${ }^{2}$, \\ Juhri Saning ${ }^{3}$, Yusriani Mangarengi ${ }^{3}$, Munawir Muhammad ${ }^{3}$, Nataniel Tandirogang ${ }^{4}$, \\ Yadi Yasir ${ }^{4}$, Masyhudi Amir ${ }^{4}$ \\ ${ }^{1}$ Molecular Biology and Immunology Laboratory for Infectious Diseases, Faculty of Medicine, Hasanuddin University, Makassar, \\ Indonesia \\ ${ }^{2}$ Department of Microbiology, Faculty of Medicine, Haluoleo University, Kendari, Indonesia \\ ${ }^{3}$ Department of Microbiology, Faculty of Medicine, Tadulako University, Palu, Indonesia \\ ${ }^{4}$ Department Microbiology, Faculty of Medicine, Mulawarman University, Samarinda, Indonesia

\section{Email address:} \\ hattaram@indosat.net.id (M. Hatta), ar_sultan2002@yahoo.com(A. R. Sultan), ressy_chan@yahoo.co.id (R. Dwiyanti), \\ destadamba@yahoo.com (M. Sabir), andini_febrianty87@yahoo.co.id (A. Febrianty), dhykao@gmail.com (A. Adhyka), \\ nurindahpurnamasari@gmail.com (N. I. Purnamasari), rezzprima@gmail.com (M. R. Primaguna),juhri.saning@yahoo.com (J. Saning), \\ yusrianiaris@yahoo.com (Y. Mangarengi),dr.munawirmuhammad@yahoo.co.id (M. Muhammad), \\ tandirogang@yahoo.com (N. Tandirogang), dryadi02@yahoo.com (Y. Yasir), masyhudiamir@yahoo.co.id (M. Amir)
}

\section{To cite this article:}

Mochammad Hatta, AndiRofian Sultan, Ressy Dwiyanti, Muhammad Sabir, Andini Febrianty, Ahmad Adhyka, Nur Indah Purnamasari, Muhammad Reza Primaguna, Juhri Saning, Yusriani Mangarengi, Munawir Muhammad, Nataniel Tandirogang, Yadi Yasir, Masyhudi Amir. The Reproducibility of the Multiplex RAPD-PCR Assay in Genotyping of Mycobacterium Tuberculosis Isolates from Sulawesi, Indonesia. American Journal of Clinical and Experimental Medicine. Vol. 2, No. 2, 2014, pp. 14-21. doi: 10.11648/j.ajcem.20140202.12

\begin{abstract}
Background: Random Amplified Polymorphic DNA (RAPD) assay has recently emerged as a genotyping method which is both robust and highly discriminatory for bacterial strain differentiation. However, RAPD assessment for Mycobacterium tuberculosiscomplex (MTC) isolates is still limited. Despite its simplicity and rapidity, conventional RAPD also has low reproducibility due to its sensitivity to several factors. Therefore we studied the feasibility of an RAPD-PCR assay to define the genetic diversity of MTC isolates and to evaluate its reproducibility.Methods:493clinical MTC isolates from the island of Sulawesi in Eastern Indonesia, collected from 2005-2012were subjected to Multiplex RAPD assay using 11 random decamer primers instead of one primer which is common in conventional RAPD. All 11 primers were found to be differentiated and produced specific RAPD profiles. The polymorphic amplicons served as RAPD markers for MTC. The dendrograms, obtained by different primers, showed the discriminatory ability of the primers.Results:Multiplex RAPD-PCR results show that the majority of the isolates from South Sulawesi, Southeast Sulawesi andCentral Sulawesiin eastern region of Indonesia belong to group MT-C (80.7\%, 80.0\% and $62.6 \%$ respectively) with result reproducibility as high as $100 \%$. Conclusion:Molecular typing with multiplex RAPD-PCR is a powerful approach to show the genetic heterogeneity of MTC isolates. The discrimination power and reproducibility of this multiple loci-based RAPD was higher than conventional fewer loci-targeted RAPD.
\end{abstract}

Keywords: RAPD-PCR, Genotyping, Mycobacterium Tuberculosis Complex, Sulawesi Indonesia

\section{Introduction}

Tuberculosis is still one of the leading causes of death by infectious diseases with 1.3 milliondeaths per year and 8.6 million new cases annually(1). Meanwhile, morethan 2 million people are infected with latent tuberculosis infection (2-4). Despitecontinuous effort in the prevention, vaccination, monitoring and treatment of tuberculosis, the diseaseremains a major health problem in many countries 
(5-8), particularly in developing countriesincluding Indonesia (9). One of the main problems is insufficient knowledge about the genetic diversity of circulating Mycobacterium tuberculosis isolates.

By applying molecular typing methods as an adjunct to the classical epidemiological approach, molecular epidemiology is an important way to study tuberculosis transmission dynamics and to learn more about the epidemiology of tuberculosis. The methods of molecular epidemiology, especially IS6110 Restricted Fragment Length Polymorphism (RFLP) of M. tuberculosis, were first introduced in outbreak investigations and its application was then gradually expanded to a populationbased study in Japan. IS6110 RFLP is obviously a powerful tool for strain differentiation of Mycobacterium tuberculosis but its labor-intensiveness limits the achievable throughput and makes it less useful for longterm prospective studies. Recently, a DNA amplificationbased method, has appeared as a substitute for or adjunct to the IS6110 RFLP, i.e., variable number of tandem repeats (VNTR) (10).Other types of assays such as MLVA allow the investigator to limit the quantity of required genotyping to only epidemiologically or phylogenetically informative markers, depending on the branch depth(regarding time) to which a given data set should to be analyzed (11). Rapid changes in Mycobacterium tuberculosis complex (MTC) genotyping methodologies have led to ongoing debate about the choice of the best genotyping strategy $(12,13)$.

Furthermore, several genetic loci within the MTC genomes are polymorphic and can be used for molecularevolutionary studies with polymerase chain reaction (PCR) or an isothermal amplification assay(14).Random Amplified Polymorphic DNA (RAPD), also known as arbitrarily primed PCR, allows the detection of polymorphisms without prior knowledge of the nucleotide sequence. The polymorphisms may serve as genetic markers to construct the genetic maps. This method utilizes short (C10 nucleotides) primers of arbitrary nucleotide sequence that are annealed in the first few cycles of PCR at low stringency. Currently, RAPD is increasingly appliedin epidemiologic typing of a wider range of microorganisms including MTC $(15,16)$. Although the technique is simple and rapid, reproducibility issues have been reported due to its sensitivity to primer variation, DNA concentration, DNA template quality, gel electrophoresis, and type of DNA polymerase (17, 18).Previous studies have shown that multiplex RAPD with ten, seven and five random decameroligonucleotide primers, respectively,in a single PCR was particularly useful for strain differentiation of Mycobacteria isolates because it is able to increase the number ofinformative genetic markers in comparison with only one round of amplification(16-18). In this prospective genotyping study covering tuberculosis transmission in the island of Sulawesi, Eastern Indonesia, we were able to show that Multiplex RAPD-PCR using 11 primers is reproducible; this technique revealed a high diversity of MTC isolates.

\section{Methods}

\subsection{Sample Collection}

Four hundred and ninety-three sputum samples from suspected tuberculosis patients were obtained from several primary health cares in South Sulawesi, Southeast Sulawesi and Central Sulawesi from 2005 to 2012. Microscopy and culture assay were performed according to the standard diagnostic methods employed at the Department of Medical Microbiology, Molecular Biology and Immunology Laboratory in Hasanuddin University, Makassar, Indonesia. Ziehl-Neelsen staining with some modifications was used for microscopic detection (19). Sputum samples were decontaminated and cultured on Lowenstein Jensen medium, which is locally produced $(20,21)$.

\subsection{DNA Preparation}

DNA was extracted from freshly collected isolate colonies of MTC according to the diatomguanidiniumisothiocyanate (GuSCN) method described by Hattaet al.(22). a loop full of the bacterial colonies was mixed with $900 \mathrm{ul}$ of lysis buffer (50 mMTris- $\mathrm{HCl}, 5.25 \mathrm{M}$ GuSCN, $20 \mathrm{mM}$ EDTA, 0.1\% Triton X-100), vortexed vigorously, and centrifuged at $1,000 \mathrm{rpm}$ for $5 \mathrm{~min}$. To obtain the DNA, samples were lysed by incubation for 15 minutes at $18^{\circ} \mathrm{C}$ and $20 \mu \mathrm{l}$ of diatom suspension was added. The diatom containing the bound DNA was centrifuged at $12,000 \times \mathrm{g}$ for 15 seconds to obtain diatom pellet. The diatom pellet was then washed with washing buffer $(5.25$ $\mathrm{M} \mathrm{GuSCN}$ in $0.1 \mathrm{M}$ Tris- $\mathrm{HCl}, \mathrm{pH} 6.4$ ), rinsed with $70 \%$ ethanol and acetone, and dried by incubation at $56^{\circ} \mathrm{C}$ for 10 minutes. The pellet was mixed with 60 ul of 10 mMTris$\mathrm{HCl}, \mathrm{pH} 8.0,1 \mathrm{mM}$ EDTA buffer and the DNA was eluted by incubation at $56^{\circ} \mathrm{C}$ for 10 minutes. After sedimentation of the diatom by centrifugation, the supernatant was collected and stored at $-20^{\circ} \mathrm{C}$ until PCR was performed.

\subsection{Molecular Fingerprint}

PCR using the RAPD method was performed with 11 primers according to Tazi et al. (16), Singh et al. [19] and Assad $M$ et al (17). DNA amplification reaction was performed in a total volume of $25 \mu \mathrm{l}$. The reaction mixture contained 1 unit of Taq DNA polymerase $0.125 ; \mathrm{MgCl} 3$, dNTP $0.5 ; 10 \times$ buffer 2.5 ; template DNA $5 \mu \mathrm{l}$; ddH2O 12,875 $\mu \mathrm{l}$ and each primer 30 pmol (A2: 5, TGCCGAGCTG 3'; R8: 5'-CCCGTTGCCT-3; U10: 5' ACCTCGGCAC 3'; U20: 5' ACCTCGGCAC 3'; OPN-01: 5' CTCACGTTGG 3'; OPN 02: 5' ACCAGGGGCA 3'; OPN-05: 5'ACTGAACGCC 3' ; OPN 09: 5' TGCCGGCTTG 3'; OPN 20: 5' GGTGCTCCGT 3'; BG65: 5' CTCGAGCGGC 3'; BG-66: 5' CGACGCTGCG 3' ). Amplification was carried out in a thermal cycler (Hybaid OMN E, UK). Following an initial denaturation (pre-PCR) step for $5 \mathrm{~min}$ at $94^{\circ} \mathrm{C}$, the cycling condition consisted of 45 cycles of the denaturation step for $1 \mathrm{~min}$ at $94^{\circ} \mathrm{C}$, the annealing step for $1 \mathrm{~min}$ at $36^{\circ} \mathrm{C}$, and the extension step for 
$1 \mathrm{~min}$ at $72^{\circ} \mathrm{C}$, followed by the final extension (post-PCR) for $5 \mathrm{~min}$ at $72^{\circ} \mathrm{C}$. Electrophoresis was performed after RAPD-PCR using $2.5 \%$ agarose gel stained with ethidium bromide and $100 \mathrm{bp}$ marker. Subsequently, the gel was visualized and photographed using a gel documentation and analysis system. Cluster analysis was performed by the unweighted-pair group method with an arithmetic mean (UPGMA) algorithm, and a rooted tree was generated (http://minisatellites.u-psud.fr). In this study, a genotype is defined as a strain with a distinct RAPD-PCR pattern. The distance between two genotypes is defined as the minimum number of changes in the data matrix composed of numerals 1 and 0 (presence: 1,or absence: 0 ).

To evaluate the stability of the methods, each sample of genomic DNA was amplified in duplicate in repeated PCRs at different times. To test for reproducibility, the DNAs from 486 isolates were extracted from 2 independent cultures. All amplifications were done with rigorously standardized concentrations of reagents, the same thermal cycler and the same cycling conditions.

\subsection{Ethical Approval}

The project received approval from the medical ethical review board of the Department of National Education of the Hasanuddin University. Oral informed consent was obtained from all study participants after explanation of the procedure and the purpose of the study. Oral informed consent was applied as the collection of the specimens did not affect the surgical procedure to any extend and all clinical data was made anonymous before analysis. The collection of informed consent was witnessed by a nurse and or the medical officer in charge and was recorded in the patient's medical file. The verbal consent procedure was approved by the medical ethical review board.

\section{Results}

42 RAPD genotypes were tested in 255 clinical isolates from South Sulawesi, 139 from Southeast Sulawesi, 99 from Central Sulawesi, and a H37Rv laboratory strain as control. Results showed that the discrimination power was increasing by different loci that associated with each other and the results reproducibility was $100 \%$. The greater the number of loci that were combined, the bigger the HunterGaston index was. For example, the Hunter-Gaston index of OPN 09 associated with OPN 02 for South Sulawesi was 0.936 , by which 126 strains could be divided into 42 groups (analyzed using the UPGMA algorithm on http://minisatellites.u-psud.fr, data not shown).

A dendogram was generated for all 493 genotypes. The dendrogram of MTC isolates showed a high degree of polymorphism therefore the genotypes were grouped in four main clusters, i.e. genomic groups MT-A,MT-B, MT-C and MT-D (figure 1).The majority of the isolates from South Sulawesi, Southeast Sulawesi and Central Sulawesi belong to group MT-C $(80.7 \%, 80.0 \%$ and $62.6 \%$, respectively)(figures2-4).Those MTC Isolates revealed a continuum of related genotypes.

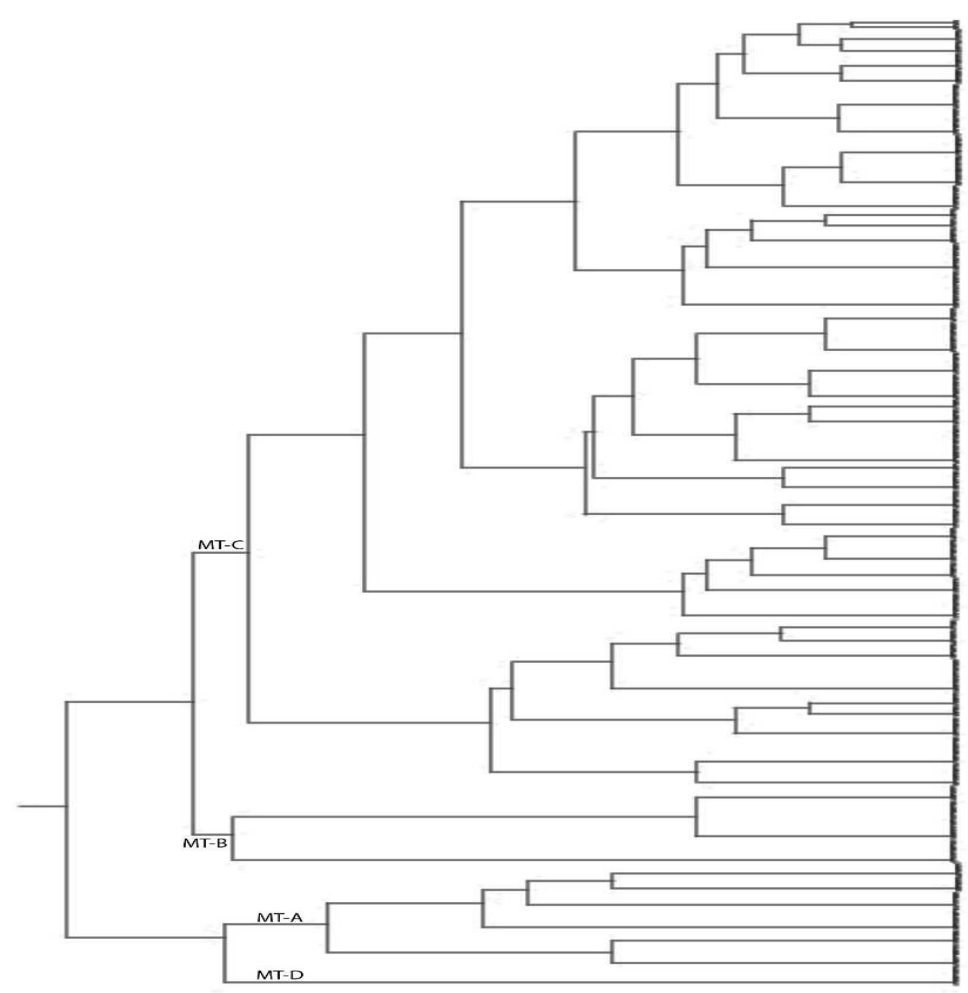

Figure 1. The dendrograph of Mycobacterium tuberculosis complex (MTC) genotypes. RAPD analysis was performed for 493 MTC sputum culture isolates from tuberculosis from eastern part of Indonesia (South, Southeast and Central Sulawesi)and H37Rv isolates from laboratory stock. Based on the variation observed at four highly variable loci a rooted tree was constructed by the unweighted-pair group method with an arithmetic mean algorithm using H37Rvstrainas reference and depicted together with the RAPD pattern and the number of isolates obtained from each genotype. 


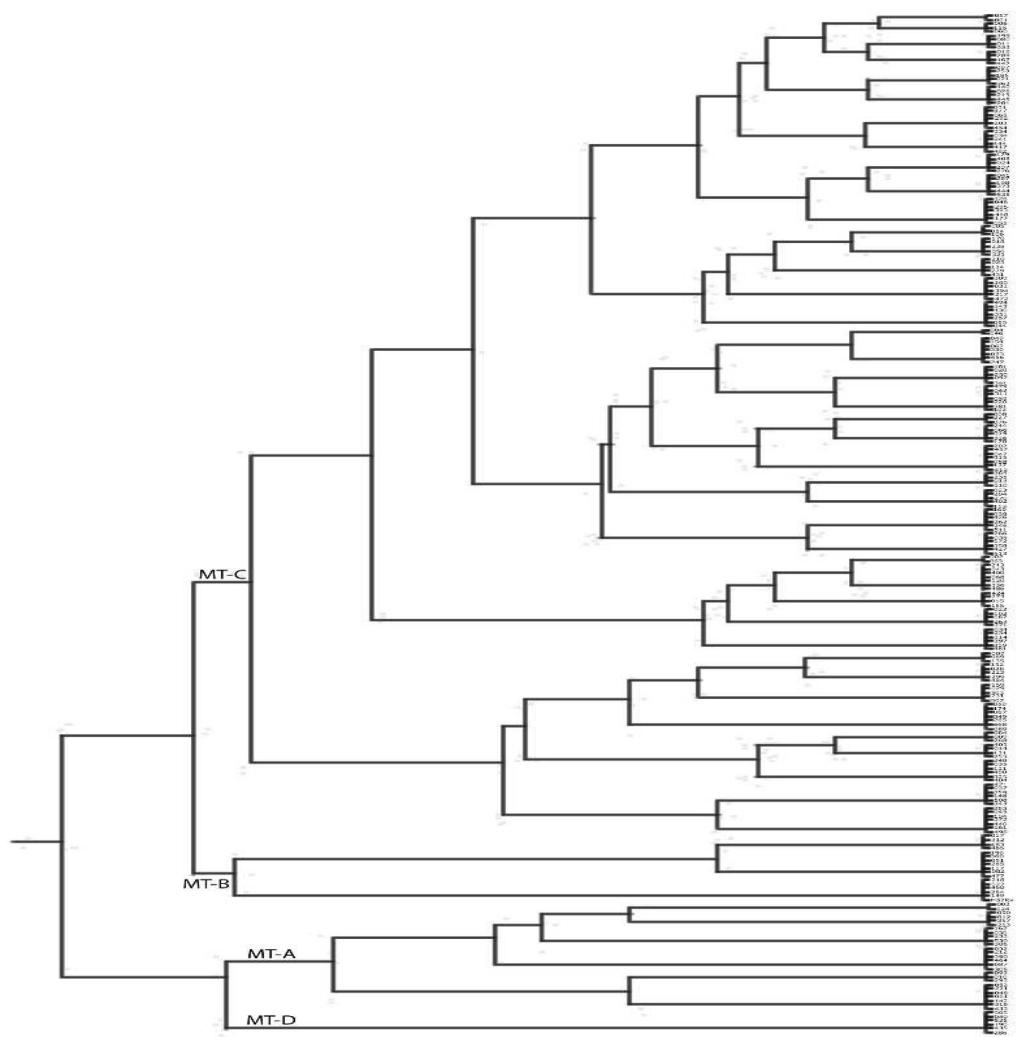

Figure 2. The dendrograph of Mycobacterium tuberculosis complex (MTC) genotypes. RAPD analysis was performed for 255 MTC sputum culture isolates from tuberculosis from South Sulawesi, Indonesia andH37Rv isolates from laboratory stock. Based on the variation observed at four highly variable loci a rooted tree was constructed by the unweighted-pair group method with an arithmetic mean algorithm using H37Rvstrainas reference and depicted together with the RAPD pattern and the number of isolates obtained from each genotype.

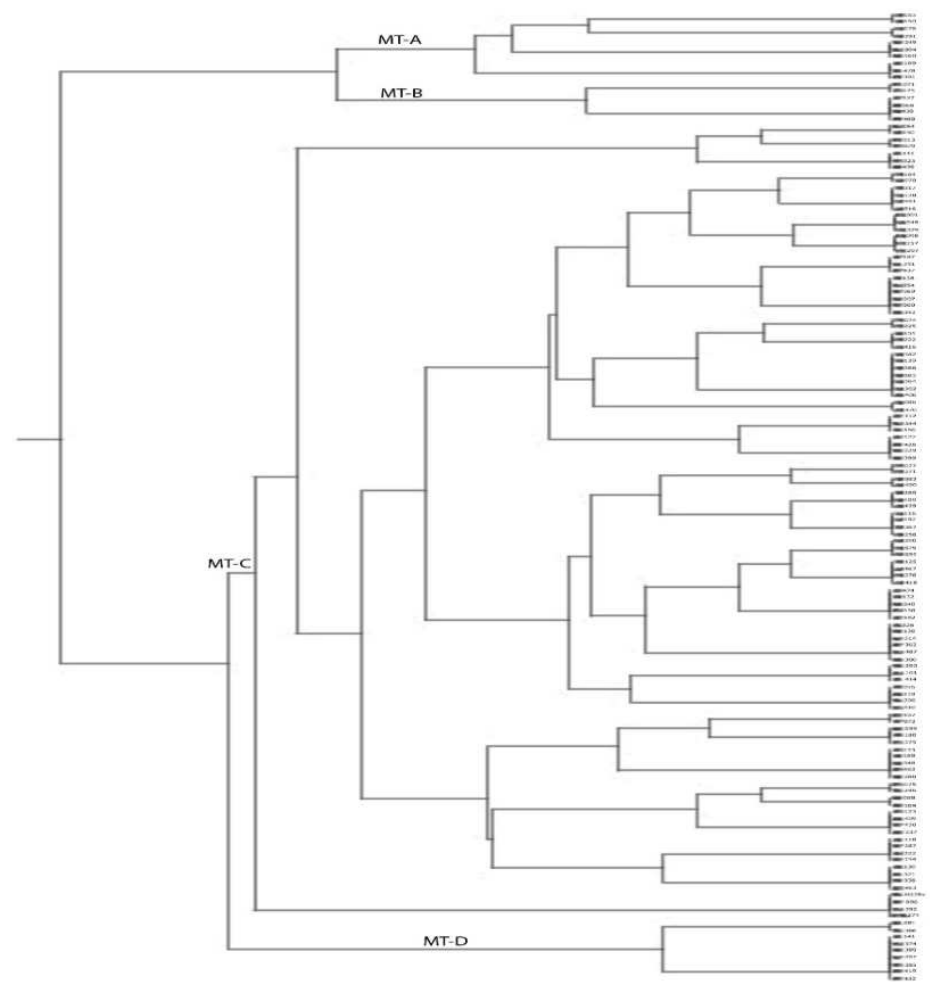

Figure 3. The dendrograph of Mycobacterium tuberculosis complex (MTC) genotypes. RAPD analysis was performed for 139 MTC sputum culture isolates from tuberculosis from Southeast Sulawesi, Indonesia andH37Rv isolates from laboratory stock. Based on the variation observed at four highly variable loci a rooted tree was constructed by the unweighted-pair group method with an arithmetic mean algorithm using H37Rvstrainas reference and depicted together with the RAPD pattern and the number of isolates obtained from each genotype. 


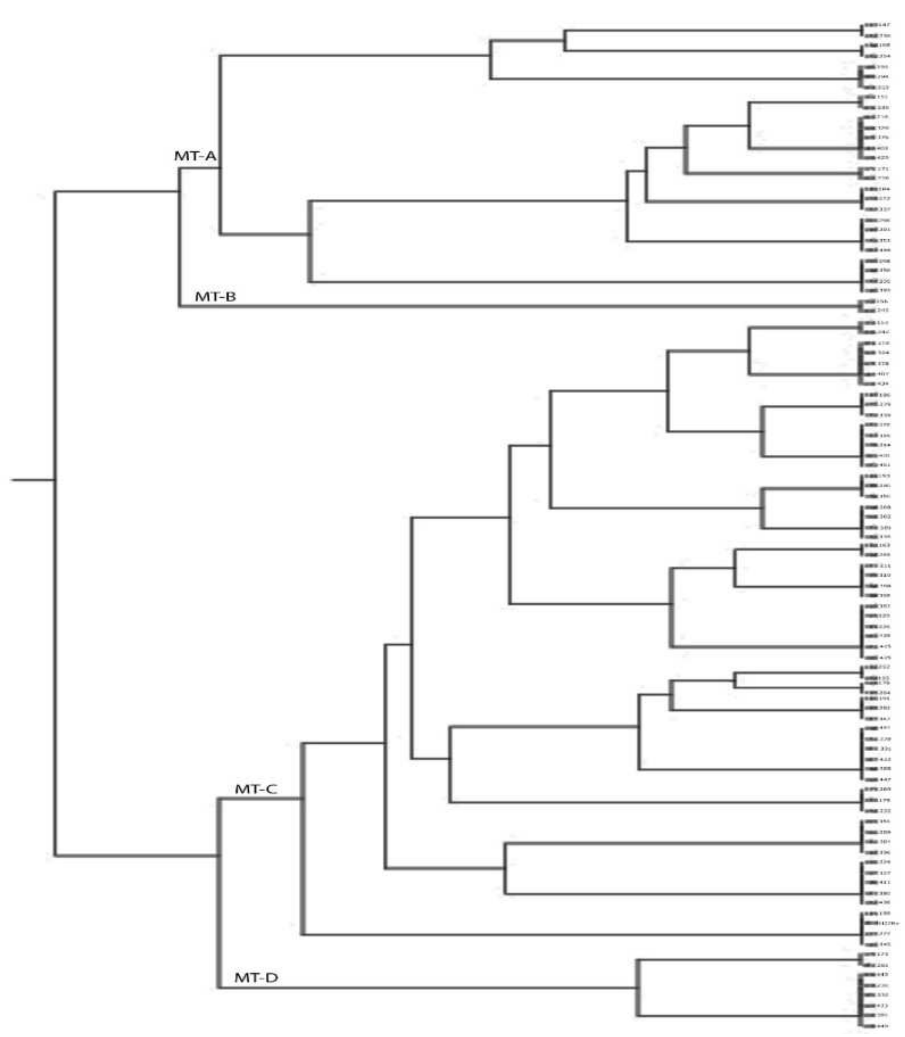

Figure 4. The dendrograph of Mycobacterium tuberculosis complex (MTC) genotypes. RAPD analysis was performed for 99 MTC sputum culture isolates from tuberculosis from Central Sulawesi, Indonesia andH37Rv isolates from laboratory stock. Based on the variation observed at four highly variable loci a rooted tree was constructed by the unweighted-pair group method with an arithmetic mean algorithm using H37Rv strain as reference and depicted together with the RAPD pattern and the number of isolates obtained from each genotype.

Table 1 shows that the genotype diversity was high, ranging from $26.2 \%$ to $83.3 \%$ of the 42 genotypes that were identified more than once, and being detected at two or all three areas. The diversity in South Sulawesi was $83.3 \%$ versus $64.3 \%$ in Central Sulawesi and $26.2 \%$ in Southeast Sulawesi (analyzed using the UPGMA algorithm on http://minisatellites.u-psud.fr, data not shown). The highest prevalent genotype was OPN 20 loci; the lowest was OPN 0.2 loci (Table 1). The OPN20loci was most prevalent in genotype MT-C and three other very similar genotypes making up a distinct branch of the genetic tree, indicating that the OPN20 loci may be captured from another bacterium on a rare occasion and subsequently spread by vertical transmission. The spatial cluster of OPN20 positive isolates in Central Sulawesi formed by the two very similar genotypes MT-A and the MT-B indicates that in that particular area either of these genotypes was introduced and that the other genotype evolved from its progeny. Furthermore, the OPN 0.2 loci was rarely prevalent in genotype MT-C, in line with findings from a previous study (17).

Table 1. Fourty two genotypes on 11 loci from 493 MTC isolates in eastern part of Indonesia.

\begin{tabular}{|c|c|c|c|c|c|c|c|c|c|c|c|}
\hline $\begin{array}{l}\text { Number of } \\
\text { isolate }\end{array}$ & A2 & $\mathbf{R 8}$ & U10 & $\mathbf{U} 20$ & OPN-01 & OPN-02 & OPN-20 & OPN-05 & OPN- 09 & BG-65 & BG-66 \\
\hline 7 & 0 & 0 & 0 & 0 & 0 & 0 & 1 & 1 & 0 & 0 & 1 \\
\hline 7 & 1 & 0 & 0 & 0 & 0 & 0 & 1 & 1 & 0 & 0 & 1 \\
\hline 7 & 0 & 1 & 0 & 0 & 0 & 0 & 1 & 1 & 0 & 0 & 1 \\
\hline 7 & 0 & 0 & 1 & 0 & 0 & 0 & 1 & 1 & 0 & 0 & 1 \\
\hline 7 & 0 & 0 & 0 & 1 & 0 & 0 & 0 & 1 & 0 & 0 & 1 \\
\hline 7 & 0 & 0 & 0 & 1 & 0 & 0 & 1 & 1 & 0 & 0 & 1 \\
\hline 8 & 1 & 1 & 1 & 0 & 1 & 1 & 0 & 1 & 0 & 1 & 0 \\
\hline 7 & 1 & 0 & 1 & 0 & 1 & 0 & 1 & 1 & 1 & 1 & 1 \\
\hline 7 & 0 & 1 & 1 & 1 & 1 & 0 & 1 & 0 & 0 & 0 & 0 \\
\hline 7 & 1 & 0 & 1 & 0 & 1 & 0 & 1 & 0 & 1 & 1 & 0 \\
\hline 7 & 1 & 1 & 1 & 1 & 1 & 0 & 1 & 0 & 0 & 1 & 0 \\
\hline 7 & 0 & 1 & 1 & 1 & 1 & 1 & 1 & 1 & 1 & 1 & 1 \\
\hline 7 & 0 & 1 & 1 & 0 & 1 & 1 & 0 & 1 & 0 & 1 & 1 \\
\hline 7 & 0 & 1 & 1 & 1 & 1 & 1 & 1 & 1 & 1 & 0 & 1 \\
\hline 11 & 0 & 0 & 1 & 0 & 1 & 0 & 1 & 0 & 1 & 1 & 0 \\
\hline 11 & 0 & 1 & 1 & 1 & 1 & 0 & 1 & 0 & 0 & 1 & 0 \\
\hline
\end{tabular}




\begin{tabular}{|c|c|c|c|c|c|c|c|c|c|c|c|}
\hline $\begin{array}{l}\text { Number of } \\
\text { isolate }\end{array}$ & A2 & R8 & U10 & U20 & OPN-01 & OPN-02 & OPN-20 & OPN-05 & OPN- 09 & BG-65 & BG-66 \\
\hline 11 & 1 & 0 & 1 & 1 & 1 & 1 & 1 & 1 & 1 & 1 & 1 \\
\hline 11 & 1 & 1 & 1 & 0 & 1 & 0 & 1 & 1 & 1 & 1 & 1 \\
\hline 11 & 0 & 1 & 0 & 0 & 1 & 0 & 0 & 0 & 1 & 0 & 0 \\
\hline 11 & 1 & 0 & 1 & 1 & 1 & 1 & 1 & 1 & 1 & 0 & 1 \\
\hline 12 & 0 & 0 & 1 & 1 & 1 & 0 & 1 & 0 & 0 & 0 & 0 \\
\hline 11 & 0 & 0 & 1 & 1 & 1 & 0 & 1 & 1 & 1 & 0 & 1 \\
\hline 11 & 1 & 1 & 1 & 0 & 1 & 0 & 1 & 0 & 1 & 1 & 0 \\
\hline 11 & 1 & 0 & 1 & 1 & 1 & 0 & 1 & 0 & 0 & 1 & 0 \\
\hline 11 & 1 & 1 & 0 & 1 & 1 & 1 & 1 & 1 & 1 & 1 & 1 \\
\hline 11 & 1 & 1 & 0 & 0 & 1 & 1 & 0 & 1 & 0 & 1 & 1 \\
\hline 11 & 1 & 0 & 0 & 0 & 1 & 0 & 1 & 1 & 1 & 1 & 0 \\
\hline 14 & 1 & 1 & 0 & 1 & 1 & 1 & 1 & 1 & 1 & 0 & 1 \\
\hline 14 & 0 & 1 & 0 & 1 & 1 & 0 & 1 & 0 & 0 & 0 & 0 \\
\hline 14 & 0 & 1 & 0 & 1 & 1 & 0 & 1 & 1 & 1 & 0 & 1 \\
\hline 15 & 1 & 0 & 0 & 0 & 1 & 0 & 1 & 0 & 1 & 1 & 0 \\
\hline 14 & 1 & 1 & 0 & 1 & 1 & 0 & 1 & 0 & 0 & 1 & 1 \\
\hline 14 & 1 & 1 & 1 & 0 & 1 & 1 & 1 & 1 & 1 & 1 & 1 \\
\hline 14 & 1 & 0 & 1 & 1 & 1 & 0 & 1 & 1 & 1 & 1 & 1 \\
\hline 14 & 0 & 1 & 0 & 1 & 0 & 0 & 1 & 0 & 0 & 0 & 0 \\
\hline 14 & 1 & 1 & 1 & 0 & 1 & 1 & 1 & 1 & 1 & 0 & 1 \\
\hline 18 & 0 & 1 & 1 & 0 & 1 & 0 & 1 & 0 & 0 & 0 & 0 \\
\hline 18 & 0 & 1 & 1 & 0 & 1 & 0 & 1 & 1 & 1 & 0 & 1 \\
\hline 21 & 1 & 0 & 1 & 1 & 1 & 0 & 1 & 0 & 1 & 1 & 0 \\
\hline 21 & 1 & 1 & 1 & 0 & 1 & 0 & 1 & 0 & 0 & 1 & 1 \\
\hline 25 & 1 & 0 & 1 & 0 & 0 & 0 & 0 & 0 & 1 & 0 & 0 \\
\hline 25 & 1 & 0 & 1 & 0 & 1 & 0 & 0 & 0 & 1 & 0 & 0 \\
\hline Percentage & 54.8 & 54.8 & 64.3 & 47.6 & 81.0 & 26.2 & 83.3 & 57.1 & 54.8 & 50.0 & 57.1 \\
\hline
\end{tabular}

\section{Discussion}

In a previous study (Maidin, et al. 2013), genetic diversity of 7 strains from the same areas in Sulawesi were analyzed by numerical analysis of RAPD PCR finger printings with five oligonucleotide primers(17).It was found that RAPD is faster and technically less demanding than most other molecular typing methods and furthermore, no DNA sequence information is necessary. Also, much smaller amounts of purified DNA are required than for methods such as RFLP. RAPD is relatively simple and useful for epidemiological analysis, but standardization of its PCR mixture and conditions are essential for its reproducibility (18). Furthermore, even with this standardization, reproducible profiles are difficult to obtain, and it is necessary to perform duplicate analysis for the true profile differences to be differentiated from experimental variation.

In this study, RAPD was modified and applied as a molecular tool for genotyping 493clinical isolates of MTC from endemic area in Sulawesi Indonesia. The resolution of this Multiplex RAPD-PCR was assessed on the basis of traditional epidemiological tracing information and RAPD data. In contrast to findings from previous studies, Multiplex RAPD-PCR assay was also able to show high reproducible results, which was one of the main issues surrounding conventional RAPD-PCR.

This study gives evidence that supports the use of RAPD analysis in determining variability within a population. This method of fingerprinting is valuable in that it is relatively easy to obtain valuable data. It allows for a more introspective interpretation of diversity within a population.
This study can also serve as a reference point for future examinations of genetic variation within populations of MTC. Furthermore, it can be a model for other studies investigating genetic diversity within a MTC strain. In this study, the use of primer OPN 20 revealed the specific DNA fragment that was most prevalent of MTC isolates. Cluster analysis of distinct genotypes may also be used to look for major sources of transmission of MTC. However, the large diversity in genotypes found in the investigated regions in Sulawesi shows that the number of tuberculosis transmission can be large. Traveling and increased migration stimulated by government-sponsored transmigration programs may have promoted the spread of particular genotypes. The stability of the RAPD loci is not known and some closely related genotypes may have arisen independently at the areas. Possibly, unique genotypes, unrelated to those found in the present study, with a more limited geographic distribution may be encountered in more remote areas.

\section{Conclusion}

Molecular typing of bacterial isolates based on polymorphisms in genomic DNA provides a powerful approach for distinguishing MTC and may provide valuable insight into the importance of different hosts and geographic regions in the maintenance and transmission of tuberculosis infection. The discrimination power and reproducibility of multiple loci RAPD was much higher than that of fewer loci. 


\section{Acknowledgments}

We are grateful to all participants of this study for their voluntary cooperation. We thank the staff from the hospitals and health centers in Makassar, South Sulawesi province, Kendari, Southeast Sulawesi province and Palu, central Sulawesi province for their enthusiasticsupport of the study.

We are indebted to the heads of District Health Departments in South, Southeast and Central Sulawesi,Dr.AgnesKwenang,Dr.Syamsulrizal,Dr.Irene,Mr. AliRotib,Mr.Hamid,Mrs.Rini,Mrs.Ina,Zr.Etty,Mrs.Eka,Mrs. Purwaningsih, Mr. Markus, and Mr. Mus Jubaru for dedicating their precious time to the supervision of clinical and laboratory examinations.

Finally, we thank Mr. Romi Usman, Mr. Marwani, Mr. Syafri, and Mr. Rochmat of the Hasanuddin University for their dedicated contributions to the field work activities and performing the blood cultures and sample preparations for molecular testing.

\section{Competing interests}

The authors declare that they have no competing interests.

\section{Authors' contributions}

$\mathrm{MH}, \mathrm{ARMS}$ and $\mathrm{RD}$ conceived and designed the experiments.MH, AR, RD, AF, AA, NIP, MRP, NT and MS carried out the molecular biology studies. MH, MS, JS, YM, $\mathrm{MM}$, and YY performed dataand specimens collection and also epidemiology, clinical and microbiologyresults analysis. $\mathrm{MH}, \mathrm{AR}, \mathrm{RD}, \mathrm{MA}$ and MS participated in the wrote the paper. Allauthors read and approved the final manuscript.

\section{References}

[1] WHO: Global Tuberculosis Report 2013. WHO Press 2013:http://www.who.int/tb/publications/global_report/en/.

[2] Connell DW, Berry M, Cooke G, Kon OM: Update on tuberculosis: $\mathrm{TB}$ in the early $21 \mathrm{st}$ century. European respiratory review : an official journal of the European Respiratory Society 2011, 20(120):71-84.

[3] Jain SK, Lamichhane G, Nimmagadda S, Pomper MG, Bishai WR: Antibiotic treatment of tuberculosis: old problem, new solution. Microbes Infect 2008, 3:6.

[4] NhlemaSimwaka B, Benson T, Salaniponi FM, Theobald SJ, Squire SB, Kemp JR: Developing a socio-economic measure to monitor access to tuberculosis services in urban Lilongwe, Malawi. Int J Tuberc Lung Dis 2007, 11(1):65-71.

[5] Caminero JA: Multidrug-resistant tuberculosis: epidemiology, risk factors and case finding. Int $\mathrm{J}$ Tuberc Lung Dis 2010, 14(4):382-390.

[6] Golub JE, Mohan CI, Comstock GW, Chaisson RE: Active case finding of tuberculosis: historical perspective and future prospects. Int J Tuberc Lung Dis 2005, 9(11):11831203.
[7] Jassal MS, Bishai WR: Epidemiology and challenges to the elimination of global tuberculosis. Clin Infect Dis 2010, 50 Suppl 3:S156-164.

[8] Kaufmann SH, Schaible UE: 100th anniversary of Robert Koch's Nobel Prize for the discovery of the tubercle bacillus. Trends Microbiol 2005, 13(10):469-475.

[9] Hatta M, Sultan AR, Tandirogang N, Masjudi, Yadi: Detection and identification of mycobacteria in sputum from suspected tuberculosis patients. BMC Res Notes 2010, 3:72.

[10] Takashima T, Iwamoto $\mathrm{T}$ : [New era in molecular epidemiology of tuberculosis in Japan]. Kekkaku: [Tuberculosis] 2006, 81(11):693-707.

[11] Gibson A, Brown T, Baker L, Drobniewski F: Can 15-locus mycobacterial interspersed repetitive unit-variable-number tandem repeat analysis provide insight into the evolution of Mycobacterium tuberculosis? Appl Environ Microbiol 2005, 71(12):8207-8213.

[12] Blackwood KS, Al-Azem A, Elliott LJ, Hershfield ES, Kabani AM: Conventional and molecular epidemiology of tuberculosis in Manitoba. BMC infectious diseases 2003, $3: 18$.

[13] Scott AN, Menzies D, Tannenbaum TN, Thibert L, Kozak R, Joseph L, Schwartzman K, Behr MA: Sensitivities and specificities of spoligotyping and mycobacterial interspersed repetitive unit-variable-number tandem repeat typing methods for studying molecular epidemiology of tuberculosis. J ClinMicrobiol 2005, 43(1):89-94.

[14] Mostowy S, Behr MA: The origin and evolution of Mycobacterium tuberculosis. Clinics in chest medicine 2005, 26(2):207-216, v-vi.

[15] Korzekwa K, Polok K, Zielinski R: Application of DNA markers to estimate genetic diversity of Mycobacterium tuberculosis strains. Polish journal of microbiology / PolskieTowarzystwoMikrobiologow $=$ The Polish Society of Microbiologists 2006, 55(1):19-24.

[16] Tazi L, El Baghdadi J, Lesjean S, Locht C, Supply P, Tibayrenc M, Banuls AL: Genetic diversity and population structure of Mycobacterium tuberculosis in Casablanca, a Moroccan city with high incidence of tuberculosis. J ClinMicrobiol 2004, 42(1):461-466.

[17] Maidin MA, Lidjaja A, Hatta M: Random Amplified Polymorphic DNA Analysis of Mycobacterium tuberculosis isolates Resistant to Isoniazid in Indonesia. J Tuberculosis Res 2013, 1:10-13.

[18] Singh JP, Verma R, Chaudhuri P: Random amplified polymorphic DNA (RAPD) analysis of Mycobacterium tuberculosis strains in India. Journal of veterinary science 2006, 7(2):181-187.

[19] deSoldenhoff R, Hatta M, Siro TW: Choosing the decolourizer and its strength to stain Mycobacterium leprae. Does it actually matter? Leprosy review 1998, 69(2):128133.

[20] Hatta M, Eka W, Zaraswati D, Rosana A, Sabir M, Yadi., Mashyudi.: Effect decontamination in identification Mycobacterium tuberculosis by $\mathrm{ZN}$ staining and PCR technique (in Indonesia). YARSI Med J 2004, 12:17-24. 
[21] Kent PT, Kubica GP: Public health mycobacteriology: A guide for level III laboratory. US Department of Health and Human Services, Center for Diseases Control, Atlanta 1985, 184.
[22] Hatta M, Smits HL: Detection of Salmonella typhi by nested polymerase chain reaction in blood, urine, and stool samples. The American journal of tropical medicine and hygiene 2007, 76(1):139-143. 